\title{
Model development for prediction of alum dosing for treatment of domestic wastewater for recycling purposes
}

\author{
$\underline{\text { Z. Aslam }}^{\text {a,b }}$, J. van Leeuwen ${ }^{a, c}$ and Neil Crossing ${ }^{b}$ \\ ${ }^{a}$ Centre for Water Management and Reuse, School of Natural and Built Environments, University of South \\ Australia, SA 5095, Australia. \\ ${ }^{b}$ Allwater, Adelaide, SA 5000, Australia.
}

${ }^{c}$ State Key Laboratory for Environmental Aquatic Chemistry, RCEES, CAS, China
Email: zeeshan.aslam@mymail.unisa.edu.au

\begin{abstract}
Removal of algae present in domestic wastewaters of stabilization ponds can be a significant challenge in the supply of recycle water for re-use purposes. Algae can be present in high numbers, especially in warm to hot summer and autumn months diminishing water quality when most needed for reuse purposes. Consequently further treatment of wastewaters may be needed for removal of turbidity and algae, prior to recycled water supply. A large recycle water treatment plant in South Australia - the Bolivar DAFF plant utilizes alum as primary coagulant for algal and suspended solids removal. Alum dosing varies significantly throughout the year, depending on source water (from stabilization ponds) quality. Algae can be present at bloom levels $\left(>10^{6}\right.$ cells per $\left.\mathrm{mL}\right)$ and the water can be at very high $\mathrm{pH}(\sim 10)$; and with high alkalinity, very high doses of alum may then be required. With this high variation in source water quality, adjustment of coagulant dosing is continually needed to be performed by operators, at times diurnally. This is done on the basis of meeting target treated water quality (of low turbidity) and minimizing costs of chemical use. Coagulant use at the plant has been highly variable, and with consideration that dosing at times, may not be at optimum. As part of continual process improvement, research was instigated to determine if model development could be achieved for prediction of coagulant dose requirements.
\end{abstract}

Data available was sourced from documented treatment plant operations over a number of years where wastewater quality varied seasonally, and from laboratory investigations incorporating jar tests and water quality analyses. These water quality parameters included untreated water algae, $\mathrm{pH}$, turbidity, ambient temperature and treatment plant daily processing volumes.

The model developed is based on apparent relationships between each of the source water qualities with alum dose rates applied at the treatment plant. Data was highly scattered for most parameters and model development was in context that error was potentially in operational dose application, as well as in model fitting i.e. that actual dosing data was not presumed to be 'true' or optima, and general trend equations might best reflect the optima. From general trend relationships and fitted algorithms of each, a model was built where the outputs of each sub-model is averaged to provide a fitted or predicted value. Model options include selection of input variables (e.g. pH, turbidity, algal number) and weighting of importance to each parameter. Treatment plant operators have accepted the model as an additional tool for decision making. In this paper the need for and the design of the model are discussed.

Keywords: Algae, modeling, Dissolved Air Flotation (DAFF), recycle water 
Aslam et al., Model development for prediction of optimum coagulant dosing of domestic wastewater for recycling purposes

\section{INTRODUCTION}

Treatment of domestic wastewaters for reuse purposes presents a range of challenges for the water industry including variance in source water quality, purpose and use of recycled water, optimization of treatment that is fit-for-purpose, costs and returns of processing and supply and client and community expectations. Challenges can be greater where recycled water demand varies seasonally, there is a range of purposes for the same recycled waters, client base and community expectations change. Despite these challenges, countries and states with intermittent or ongoing water supply shortages have moved towards recycling of wastewaters, both domestic and industrial, in efforts to secure water resources. Purposes can vary including for drinking water supply, intensive horticulture, pasture and domestic, non-potable use.

South Australia is a dry state of the Australian continent, which experiences the effects of climate cycling from wet (La Niña) to dry (El Niño) periods, and with some events being severe and of long duration. Water resources in this state are limited and highly dependent on inflows from the Murray-Darling Basin. In attempts to secure water resources, state government and council actions have included domestic wastewater recycling for horticulture, domestic (non-potable) uses, watering of council lands, parklands and vineyards.

Recycling of domestic wastewaters can involve a range of treatment processes, including membrane bioreactors, physical membrane filtration, activated sludge (ActS), denitrification (DeN), secondary aerobic/stabilization ponds (SPs), coagulation, dissolved air flotation and filtration (DAFF) and chemical disinfection. With the application of SPs for treatment of wastewaters, (micro-) algae provide benefit in terms of providing oxygen for bacteria that mineralize organics, remove nutrients and pathogens (de Godos et al. 2011). However, these can be problematic when the algal growth is high and waters are to be used in supply of recycled water for, example in horticulture and for domestic use. The incidence of algal blooms increases at higher temperatures (Sweeney et al. 2005) and high algal growth in SPs in warm to hot temperature months can affect water quality by causing high turbidity and high $\mathrm{pH}(\sim 10)$. The $\mathrm{pH}$ can also vary daily due to algae removing carbon dioxide in daylight hours via photosynthesis, resulting in increasing levels of hydroxide, and at night, through respiration, carbon dioxide is produced which lowers hydroxide ion concentration and consequently, the $\mathrm{pH}$ (NCDENR, 2015).

Coagulation followed by DAFF can be applied for removal of a range of pollutants from waters including colloids, fine particles, microorganisms, dissolved organic compounds, and dispersed and emulsified oils (Matis and Lazaridis, 2002; Rubio et al., 2002; Ross et al., 2003; Carissimi and Rubio, 2005). Coagulation \& DAFF are applied for treating surface waters of low mineral turbidity, containing algae, natural color and natural organic matter, in the supply of potable waters, and for treating wastewaters from food processing.

Modelling of treatment processes for potable water supply has been regularly reported in the literature, including by Baxter et al. (1999), Kastl et al. (2004), van Leeuwen et al. (2005, 2009), Trinh and Kang (2011) and Heddam and Dechemi (2015). Generally, these models are based on experiential relationships between raw and treated water quality and treatment conditions required to achieve a targeted water quality. They include models designed for removal of colour, turbidity and organic matter and for coagulant dose prediction. Studies have also been conducted for development of effective mathematical methods and models to determine optimum coagulant doses for treatment of wastewaters, including by Huang et al. (2009), Khayet et al. (2011), Tzfati et al. (2011) and Subramonian et al. (2015).

In this paper, we report a simple model approach to estimate alum dose requirements for removal of algae and turbidity from a domestic wastewater used for recycled water purposes. Available data was from treatment plant operations. The aim of this model is to provide plant operators with a guide for coagulant dose determination which results in recycled waters meeting contractual requirements and minimizes over dosing of coagulant.

\section{MATERIALS AND METHODS.}

2.1. Data collection: Data was sourced from the operations of a major wastewater treatment system of South Australia (Bolivar Wastewater Treatment Plant). The system comprises an activated sludge plant, nitrification/denitrification, stabilization ponds and tertiary treatment [alum $\left(\mathrm{Al}_{2}\left(\mathrm{SO}_{4}\right)_{3}: 18 \mathrm{H}_{2} \mathrm{O}\right)$ coagulation, flocculation, dissolved air flotation, filtration and chlorination]. Source waters of the DAFF plant are from stabilization ponds (of $\sim 16$ days HRT after prior activated sludge treatment). Data was acquired of the source water quality to the DAFF plant including algae concentration, $\mathrm{pH}$, turbidity and daily average temperature and treatment plant daily process volumes. Source water quality and coagulant dose data acquired from operational records were found to be highly scattered, reflecting high variance in dosing applied in context of the source water quality. Alum dose selection for plant wastewater treatment is based on achieving low filtered 
Aslam et al., Model development for prediction of optimum coagulant dosing of domestic wastewater for recycling purposes

turbidity $(<0.5 \mathrm{NTU}$, for $95 \%$ of each day of a contractual year) for recycled water supply. Other criteria are (a) E coli, $<10$ cells per $100 \mathrm{~mL}$, (b) total dissolved solids, $<1500 \mathrm{mg} / \mathrm{L}$ for $99 \%$ of each day of a contractual year, (c) pH of filtered water, from 6.0 to 8.5 for $99 \%$ of each day of a contractual year.

2.2. Turbidity and pH: Turbidity, in Nephelometric Turbidity Unit (NTU), was measured using a HACH ratio turbidimeter (Model 2100N USA). For pH measurement, a EUTECH pH 700 bench pH meter was used to determine the $\mathrm{pH}$ of the raw waters.

2.3. Algae: Algae numbers were determined by a standard method described in Standard Methods for the Examination of Water and Wastewater (22 nd edition 2012).

2.4. Modeling: Models were developed using Table Curve $\subset$ software $2 \mathrm{D}$ Windows v4.00 and Microsoft Excel.

\section{RESULTS AND DISCUSSION}

The aim of model development was to enable prediction of alum doses for tertiary treatment (coagulation, dissolved aeration, floc flotation and filtration, 'DAFF') of wastewaters previously treated by activated sludge (ActS) and stabilization ponds (SPs). This treatment train is applied to domestic wastewaters used in intensive horticulture [North Adelaide Plains, (NAP)] and for supply of recycle water to housing developments with 'third pipe' connection, such as the suburb of Mawson Lakes, South Australia. Source water quality data (post ActS) and SPs treated wastewater that supplies the DAFF treatment plant was used for model development. This data included algae concentration (cells $/ \mathrm{mL}$ ), $\mathrm{pH}$, turbidity $(\mathrm{NTU})$, temperature ${ }^{0} \mathrm{C}$ (daily average) and DAFF plant treated water supply (in megalitres per day, MLD). Source water quality (SWQ) data and of coagulant use were obtained from plant operations between January 2010 and January 2015. Available SWQ data were graphed against alum doses applied at the DAFF plant to investigate potential relationships, and these are shown below (figures $1 \mathrm{a} \& \mathrm{~b}$ and $2 \mathrm{a}, \mathrm{b} \& \mathrm{c}$ ). The data are highly scattered, and this indicates high variance in doses applied in relation to water quality parameters investigated; e.g. algae concentration (Fig. 1a). This may be due to other factors besides algae influencing dose selection in treatment operations and/or, high variance (error) where optima doses are difficult to determine and sub-optima doses are used at high frequency. Another factor for consideration is that some data are not independent (in this case study), e.g. $\mathrm{pH}$ and turbidity are directly related to algae concentrations of the source water.

It is well known within the wastewater industry that high doses are generally needed when the algae concentration and turbidity of source waters are high. Algae numbers in stabilization ponds are generally higher in the warmer, drier weather periods of the year, (late spring, summer, and early autumn) and when supply from the DAFF plant to the horticulture industry and households increases. Hence, for model development, alum dosing is generally positively correlated with algae concentration, turbidity, $\mathrm{pH}$, temperature and daily water volumes treated at the DAFF plant, despite the actual data being high scattered. Although these parameters are not independent, model development was primarily performed on these being considered to be independent, and where a forced fit of each parameter was related to alum. This was done to allow operator use of any one or all of the five parameters, based on their availability and level of operator confidence on the parameter that might vary seasonally, and over time. SWQ can change rapidly and some data may not be acquired in time (laboratory analyses may take several days) for consideration of the most suitable coagulant dose e.g. algae concentration.

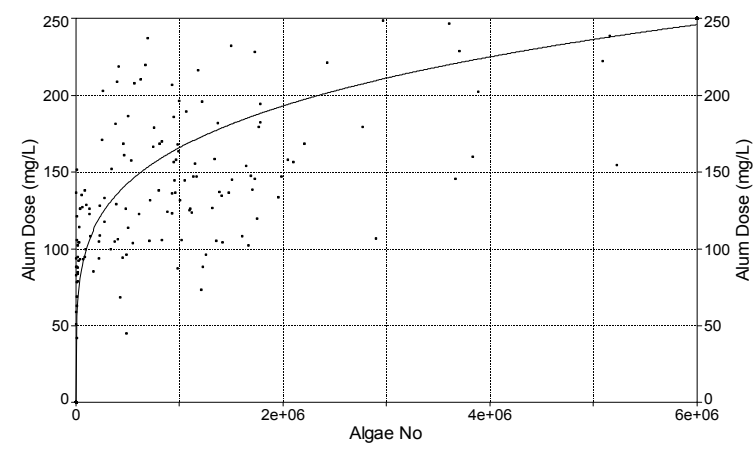

Figure 1a. Relationship between alum doses applied at the wastewater treatment plant and algae (cells $/ \mathrm{mL}$ ).

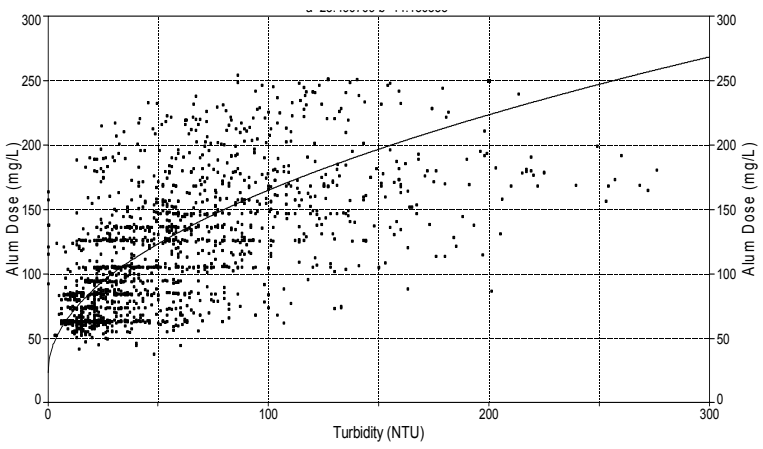

Figure 1b. Relationship between alum dose and turbidity. 
Aslam et al., Model development for prediction of optimum coagulant dosing of domestic wastewater for recycling purposes

Hence, each parameter was independently correlated with alum dosing as applied over the study period.

Data of algae concentration versus alum dose is given in Figure 1a, and the fitted algorithm is given below (Eq. 1). The function was forced through the origin on the basis that theoretically, source water without any algae present (and assuming very low turbidity) should require little or no alum treatment.

For algae concentration $\left(\frac{\text { cells }}{\mathrm{mL}}\right)$, Alum Dose $=7.9212 *\left(\right.$ algae $\left.^{0.22105}\right)$

A graph of data of turbidity versus alum dose is shown in Figure $1 \mathrm{~b}$ and the equation (Eq. 2) of this relationship is given below,

For turbidity, (NTU), Alum Dose $=23.5+14.15 *$ turbidity $^{0.5}$

The graph of average daily temperature and alum dose applied on that corresponding day, is shown in Figure $2 \mathrm{a}$.

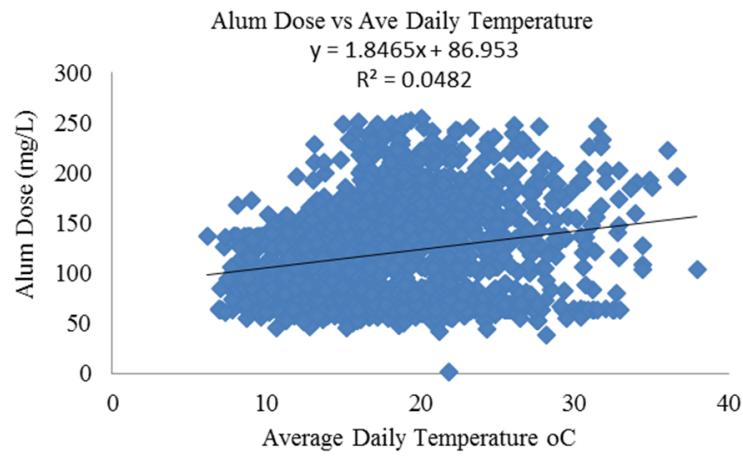

Figure 2a. Data of the average daily temperatures $\left({ }^{\circ} \mathrm{C}\right)$ and alum doses applied at the wastewater treatment plant.

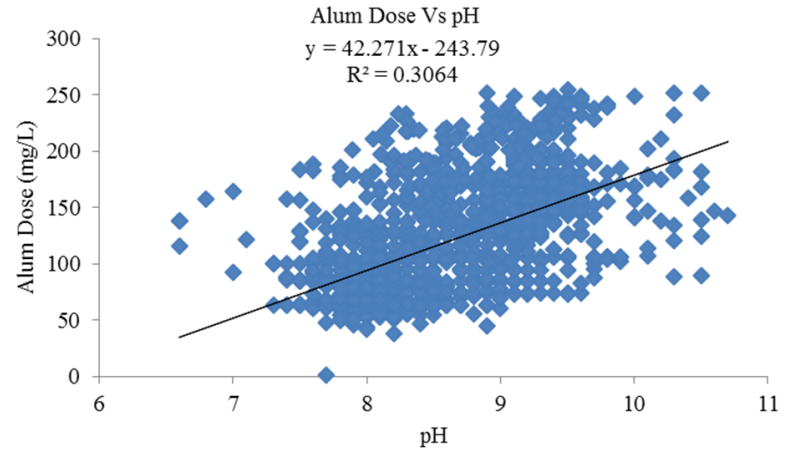

Figure 2b. Data of $\mathrm{pH}$ of the source water and corresponding alum doses applied at the treatment plant.

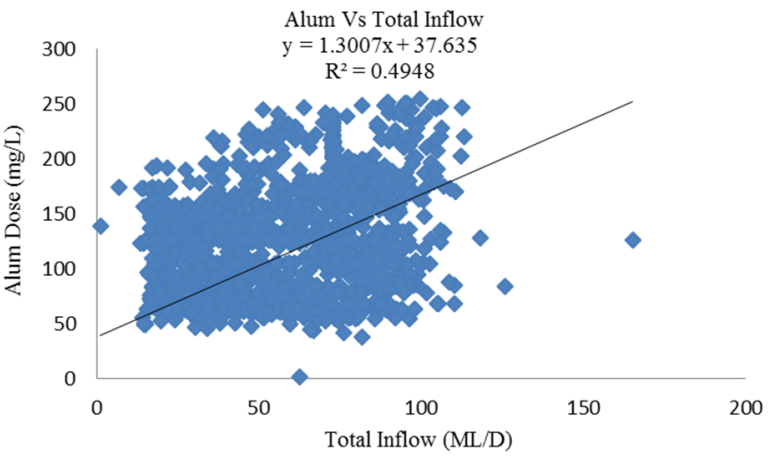

Figure 2c. Data of inflow (MLD) to the DAFF plant.

The data shown in Figure 2a is highly scattered and there is little evidence of any clear relationship between the two parameters. Disregarding the full operational data set for acquiring a best fitted algorithm, data was selected of the apparent extremes of the parameters $\left\{\right.$ (i) $\sim 7^{\circ} \mathrm{C}$ and $45 \mathrm{mg} / \mathrm{L}$ alum; and (ii) $\sim 36^{\circ} \mathrm{C}$ and $247 \mathrm{mg} / \mathrm{L}$ alum $\}$ from which a simple linear equation was determined, i.e.

For average daily temperature, Alum Dose $=6.96551 *$ temperature -3.785

For the parameters tested (average daily temperature, $\mathrm{pH}$ and total daily inflow), the $\mathrm{R}^{2}$ values vary but all are low. From this data only very general relationships (linear) can be considered and likely to have a high level of error and/or confounding with other unknown factors. Consequently, a similar approach was adopted to form a relationship between $\mathrm{pH}$ and alum dosing, where the 'extremes' of the data were selected for fitting of a simple linear function (Figure $2 b$ ).

Data used to fit a linear relation are as follows: (i) $\mathrm{pH} 7$ and $40 \mathrm{mg} / \mathrm{L}$ alum, (ii) $\mathrm{pH} 10$ and $250 \mathrm{mg} / \mathrm{L}$ alum.

For $\mathrm{pH}$ of the source water, Alum Dose $=70 * \mathrm{pH}-450$ 
Aslam et al., Model development for prediction of optimum coagulant dosing of domestic wastewater for recycling purposes

Data of source water daily inflow (MLD) to the DAFF plant (which, following coagulation and DAFF treatment, is distributed to customers) are shown in Figure 2c. This data indicates a weak (if any) relationship between inflow and alum dose rates applied at the plant. The processing of the water at the DAFF plant is generally highest in the warmest/driest period of the year (summer-autumn) and least in the winter period when natural rainfall meets the needs of the horticulture areas of the NAP and recycled water demand is low. From these data, minimum and maximum inflows with associated alum dosing were estimated, i.e.

(i) Minimum $15 \mathrm{ML} / \mathrm{D}$ and $40 \mathrm{mg} / \mathrm{L}$ alum

(ii) Maximum, $112 \mathrm{ML} / \mathrm{D}$ and $247 \mathrm{mg} / \mathrm{L}$ alum.

The assumed straight line relationship is as follows:

For 15 MLD (minimum) and 112 MLD (maximum),

Alum Dose $=2.031 *$ MLD +19.536

The basis for selection of the minimal inflow is that this represents the processing volume in winter when the supply demand is least and conversely, the $112 \mathrm{ML} / \mathrm{D}$ represents the supply in the peak demand period, when conditions are driest (and weather conditions are at high temperatures). Unlike other parameters such as $\mathrm{pH}$ and temperature which are fixed, the volumes of treated water may vary based on supply demand and plant capacity. Hence the selected minimum and maximum MLD values may change. To account for this, the minimum and maximum data are entered into the model, from which a line gradient ( $\triangle \mathrm{MLD} / \triangle \mathrm{Alum})$ and the (alum) intercept are determined and applied.

From equations 1 to 5, five alum doses are estimated from the five parameters. The final 'predicted' alum dose can be determined by several ways, from individual doses calculated from the five types of input data and equations 1 to 5 , including,

(1) The mean of all equation determined alum doses,

(2) The mean of operator selected equations where some parameters are used but not all,

(3) By assigning weighting factors to some parameters to increase their influence on a final alum dose, for example if algae is considered to have five times the influence on alum dose needs than temperature, then the dose prediction of Eq 1 is multiplied by 5, this is added to the dose prediction for temperature (Eq. 3) and the average calculated.

ANOVA was performed on the factors that were assumed to influence dose selection. A fitted model (MV1) using the five available factors (Eq. 6), another (MV2) using algae, pH and turbidity (Eq. 7) and a third (MV3) using algae, total inflow rate and turbidity (Eq. 8) are shown below. MV2 and MV3 are examples using selected key factors in potential model options.

MV1: Alum dose $(\mathrm{mg} / \mathrm{L})=$

Algae*0.207 - Temp*0.031- MLD*0.0346+pH*0.456+Turbidity*0.514 - 47.3

MV2: Alum dose $(\mathrm{mg} / \mathrm{L})=$ Algae $* 0.214+\mathrm{pH}^{*} 0.415+$ Turbidity*0.504-47.0, and

MV3: Alum dose $(\mathrm{mg} / \mathrm{L})=$ Algae $* 0.196+\mathrm{MLD} * 0.018+$ Turbidity $* 0.290+42.6$

The various models were integrated into Microsoft Excel (see Figure 3) where alum doses are predicted from the known influencing factors. Treatment plant managers (and operators) can choose which parameters should be applied and their assigned weightings. Subsequently, treatment plant operators input data into the model from which an average dose is determined, and this can be compared to the statistically determined doses. The most suitable dose can be based on selection of the most conservative dose (but with the highest risk of overdosing) or by averaging of the various doses calculated. Generally however, the doses predicted should be similar to each other, as demonstrated in Figure 3.

Other models reported in the literature are based on more complex mathematical approaches such as Response Surface Methodology (Khayet et al. 2011; Trinh and Kang, 2011), Partial Order Scaling Analysis (Tzfati et al. 2011) and Neural Fuzzy Inference System (Heddam and Dechemi, 2015). In these applications,

data were acquired under controlled laboratory conditions such as by jar tests and in doing so, high reliance might can be placed on the data. For this study, data was predominantly acquired from full-scale operations where dose selection might have varied because of undefined influences, such as individual operator assessment of coagulant requirements and variance in dose adjustment response time with water quality change. The highly scattered data indicates incomplete identification of key factors influencing coagulant dose 
Aslam et al., Model development for prediction of optimum coagulant dosing of domestic wastewater for recycling purposes

needs and/or substantial dosing variation in context of source water quality (potentially error) and hence very general relationships were established and applied.

\begin{tabular}{|c|c|c|c|c|}
\hline \multicolumn{5}{|c|}{ DAFF Plant : Alum Dose Prediction Model Version 20150324} \\
\hline \multirow[b]{2}{*}{ Row } & Column & E & $\mathrm{F}$ & G \\
\hline & \begin{tabular}{|l|} 
Raw Water \\
Parameter
\end{tabular} & Data Entry & $\begin{array}{l}\text { Importance Factor } \\
\text { Plant Data (1 to 10) }\end{array}$ & $\begin{array}{l}\text { Plant Based } \\
\text { Prediction }\end{array}$ \\
\hline 10 & Algae cells $/ \mathrm{mL}$ & $5,000,000$ & 1 & 240 \\
\hline 11 & Mean Daily Temp $\left(5-35^{\circ} \mathrm{C}\right)$ & 25 & 1 & 170 \\
\hline 12 & MLD & 120 & 1 & 240 \\
\hline 13 & $\mathrm{pH}(7-10.5)$ & 10 & 1 & 250 \\
\hline 14 & Turbidity & 156 & 1 & 200 \\
\hline \multirow[t]{3}{*}{15} & Mean Alum Dose Prediction & \multicolumn{2}{|c|}{ Operator selected 'Importance Factor'ş } & 220 \\
\hline & Mean Alum Dose Prediction & \multicolumn{2}{|c|}{ Statisical Determined Dose (all parameters)* } & 206 \\
\hline & Mean Alum Dose Prediction & \multicolumn{2}{|c|}{ Statisical Determined Dose (Algae, $\mathrm{pH}$, Turb.) ${ }^{*}$} & 209 \\
\hline St Kilda DAFF Plant & Data Entry & Developed by & Alum Dose $(\mathrm{mg} / \mathrm{L})$ as $\mathrm{Al}_{2}\left(\mathrm{SO}_{4}\right)$ & $: 18 \mathrm{H}_{2} \mathrm{O}$ \\
\hline Mean Low MLD (Winter) & 15 & UniSA & & \\
\hline Alum dose at Low MLD & 50 & 2015 & Data Entry & \\
\hline Mean High MLD (Summer) & 124 & & & \\
\hline Alum dose at High MLD & 247 & & & \\
\hline & \$No entry of an Importance $F$ & actor $=$ Prediction & t included in average pre & n calculation \\
\hline
\end{tabular}

Figure 3. Model applied at the DAFF wastewater treatment plant.

The model described has been made available to operators to assist them in determining alum dosing at the wastewater treatment plant. Weighting of factors are assigned by plant operators and can be altered as these factors change in their importance on coagulant dose selection. Over a period of several months of implementation, user response has been that the model is beneficial in decision making for dose selection, supporting the established approaches applied for dose selection. Established methods are based on dose adjustment to meet contractual requirements to achieve treated (post DAFF) recycle water quality.

\section{CONCLUSIONS}

The model described is site specific and was developed for estimating coagulant (alum) doses for treatment of a wastewater sourced from stabilization ponds, to be used for recycling purposes. The wastewater can vary highly in water quality (e.g. turbidity, $\mathrm{pH}$ and algae numbers) throughout the year, requiring continual adjustment of dosing levels. The model comprises a series of simple algorithms that empirically relate applied alum doses to apparent related factors. Dose estimation can be made from one or all of the factors investigated. Treatment plant operators have accepted the model as an additional tool for prediction of alum dosing which is considered in their decision making for optimized treatment.

\section{REFERENCES}

Baxter, C.W., Shariff, R., Stanley, S.L., Smith, D.W., Zhang, Q. and Saumer, E.D. (1997). Model based advanced process control of coagulation. Water Science and Technology, 45(4-5), 9-17.

Carissimi, E. and Rubio, J., (2005). Advances in particulates aggregation- flotation separation. Proceedings in Centenary of Flotation Symposium, Brisbane, Australia, 415-423.

de Godos, I., Guzman, H.O., Soto, R., García-Encin, P.A., Becares, E., Muñoz, R. and Vargas, V.A. (2011). Coagulation/flocculation-based removal of algal-bacterial biomass from piggery wastewater treatment. Bioresource Technology, 102, 923-927.

Heddam, S. and Dechemi, N. (2015). A new approach based on the dynamic evolving neural-fuzzy inference system (DENFIS) for modelling coagulant dosage (Dos): case study of water treatment plant of Algeria. Desalination and Water Treatment, 53, 1045-1053.

Huang M., Ma Y., Wan J. and Wang Y. (2009). Simulation of a paper mill wastewater treatment using a fuzzy neural network. Expert Systems with Applications, 36, 5064-5070

Kastl, G., Fisher, I., Sathasivan, A. and van Leeuwen, J. (2004). Modelling DOC removal by enhanced coagulation. Journal of the American Water works Association, 96(2), 79-89. 
Aslam et al., Model development for prediction of optimum coagulant dosing of domestic wastewater for recycling purposes

Khayet, M., Zahrim, A.Y., and Hilal. N. (2011). Modelling and optimization of coagulation of highly concentrated industrial grade leather dye by response surface methodology. Chemical Engineering Journal, $167,77-83$.

Matis, K.A. and Lazaridis, N.K. (2002). Flotation techniques in water technology for metals recovery: dispersed-air vs. dissolved air flotation. Journal of Mining and Metallurgy, 38 (1-4 A), 1-27.

NCDENR, North Carolina Department of Environment and Natural Resources, Division of Water Resources, Raleigh, NC 27699-1601, http://portal.ncdenr.org/web/wq/ess/eco/blooms accessed 2072015.

Ross, C.C., Valentine, G.E., Smith, B.M. and Pierce, J.P. (2003). Recent advances and applications of dissolved air flotation for industrial pretreatment. Presented at: The Industrial Water/Wastewater Program North Carolina AWWA/WEA Conference, Greensboro-North Carolina.

Rubio, J., Souza, M.L. and Smith, R.W. (2002). Overview of flotation as a wastewater treatment technique. Minerals Engineering ,15, 139-155.

Sweeney, D.G., O’Brien, M.J., Cromar, N.J. and Fallowfield, H.J. (2005). Changes in waste stabilisation pond performance resulting from the retrofit of activated sludge treatment upstream: part II - management and operating issues. Water Science and Technology, 51 (12), 17-22.

Subramonian, W., Wu, T.Y., Chai, S-P. (2015). An application of response surface methodology for optimizing coagulation process of raw industrial effluent using Cassia obtusifolia seed gum together with alum. Industrial Crops and Products , 70, 107-115

Trinh, T.H. and Kang, L.S. (2011). Response surface methodological approach to optimize the coagulationflocculation process in drinking water treatment. Chemical Engineering Research and Design, 89, 1126-1135.

Tzfati, E., Sein, M., Rubinov, A., Raveh, A. and Bick, A. (2011). Pretreatment of wastewater: Optimal coagulant selection using Partial Order Scaling Analysis (POSA). Journal of Hazardous Materials, 190, 5159.

van Leeuwen, J., Daly, R. and Holmes, M. (2005). Modelling the Treatment of Drinking Water to Maximize, dissolved organic matter removal and minimize disinfection by-product formation. Desalination, 177, 81-89.

van Leeuwen, J., Holmes, M., Kaeding, U., Daly, R. and Bursill, D. (2009). Development and Implementation of the software mEnCo $\subset$ to Predict Coagulant Doses for DOC removal at Full-Scale WTP's in South Australia. Journal of Water Supply: Research and Technology-AQUA, 58(4), 291-298. 